\title{
Retinoblastoma cT3a TNM Finding v7
}

National Cancer Institute

\section{Source}

National Cancer Institute. Retinoblastoma cT3a TNM Finding v7. NCI Thesaurus. Code C88762.

Tumor fills more than $2 / 3$ of the eye. (from AJCC 7th Ed.) 